\section{A "luta contra a morte": os corpos, modernidade brasileira e uma história da velhice, São Paulo e Rio de Janeiro, década de 1930}

\author{
The "fight against death:" \\ bodies, Brazilian modernity, \\ and a history of old age, São \\ Paulo and Rio de Janeiro, \\ 1930s
}

Edivaldo Gois $J r^{i}$

Professor, Departamento de Educação Física e Humanidades/ Universidade Estadual de Campinas. Campinas - SP - Brasil orcid.org/0000-0002-0521-1937 edivaldo@fef.unicamp.br
GOIS JR., Edivaldo. A "luta contra a morte": os corpos, modernidade brasileira e uma história da velhice, São Paulo e Rio de Janeiro, década de 1930. História, Ciências, Saúde-Manguinhos, Rio de Janeiro, v.27, n.1, jan.-mar. 2020, p.93-113.

Resumo

O estudo investiga como a velhice era representada em uma modernidade brasileira na década de 1930 . Foi realizada uma pesquisa histórica que teve como fontes periódicos médicos e, principalmente, jornais e revistas das cidades de São Paulo e do Rio de Janeiro. A pesquisa demonstrou que as particularidades e contradições de uma modernidade brasileira contribuíram para uma variedade de representações da velhice. A análise do corpo documental impediu uma descrição homogênea da velhice, mas atestou considerável aumento do poder dos saberes científico e médico sobre os comportamentos considerados adequados em relação aos corpos na década de 1930.

Palavras-chave: história do corpo; história da ciência; velhice.

\section{Abstract}

The way old age was depicted during the 1930s, in Brazilian modernity, is investigated. A historical study was conducted using as its sources newspapers and magazines published in São Paulo and Rio de Janeiro, as well as medical periodicals. It showed that the particularities and contradictions of Brazilian modernity contributed to a variety of representations of old age. The analysis of the documentary corpus failed to reveal a homogenous description of old age, but identified a considerable increase in the power of scientific and medical knowledge about behaviors considered adequate with regard to bodies in the 1930s.

Keywords: history of the body; history of science; old age. 
C omo a velhice era representada na década de 1930 nas cidades de São Paulo e do Rio de Janeiro? ${ }^{1}$ Ao problematizar a velhice, é preciso sublinhar que a década de 1930 foi um período de reinvindicações das classes trabalhadoras no campo político, o que também motivou a organização de um sistema previdenciário no país. Júlio Simões (2000) nos explica que o sistema previdenciário brasileiro foi concebido como um seguro social com contribuições compulsórias por parte das empresas, dos empregados e do governo, em um regime de capitalização gerido pelo Estado. A organização desse sistema previdenciário, paradoxalmente, também foi relevante no controle dos movimentos operários, uma vez que o Estado se colocava como mediador das relações entre o capital e o trabalho. Além disso, ao conceder a aposentadoria, o Estado também disciplinava os trabalhadores em uma ética de conservação, pontualidade e fidelidade ao emprego (Simões, 2000).

Dessa forma, o tema da velhice ocupava as lutas políticas, mesmo em um país com uma população jovem como o Brasil, que, em 1939, segundo dados do Anuário Estatístico, possuía apenas $3,72 \%$ da população com mais de 60 anos, o equivalente a 1.675 .534 idosos para 45.002.176 habitantes. O quadro não era diferente na capital do país, a cidade do Rio de Janeiro, com apenas 4,53\% de sua população com mais de 60 anos (IBGE, 1939, 1946).

No entanto, além das lutas políticas, no campo cultural as representações sobre a velhice não eram determinadas apenas por faixa etária, pois delimitavam um processo que não era definido biologicamente, mas sobretudo "socialmente produzido" (Debert, 2006), pois "a idade cronológica, nas sociedades ocidentais, é estabelecida por um aparato cultural" (Debert, 2004, p.47) ou ainda, como argumenta Stephen Katz (1998), por meio de "tecnologias de diferenciação" que dão destaque às diferentes etapas do "curso da vida moderno", possibilitando diferentes papéis sociais desempenhados por grupos de indivíduos pautados pela idade. Nesse sentido, em relação ao envelhecimento, essas tecnologias podem ser compreendidas principalmente pelo incremento de conhecimentos científicos especializados em idosos, na sistematização de aposentadorias e pensões e na crescente organização de asilos (Katz, 1998; Groisman, 1999).

A presente pesquisa, mais especificamente, centrou-se na relação dos conhecimentos científicos sobre a velhice mediante suas possíveis representações em um projeto de modernidade em cidades brasileiras. Assumimos o termo "velhice" porque, até os anos 1960, ele era amplamente utilizado para se referir a esse grupo etário simplesmente denominado "velho", o que não era considerado pejorativo (Peixoto, 2006), já que a palavra "idoso" raras vezes era pronunciada. Também podemos observar nas fontes que, na década de 1930, "velho", "velha" e "velhice" eram palavras muito mais recorrentes e evidenciavam diversas representações acerca do envelhecer.

Neste estudo, o conceito de "representações" (Chartier, 1991) é fundamental, pois nos permite perceber a dimensão simbólica dos discursos em relação às práticas. Desse modo, as representações sobre velhice não são discursos neutros, visto que produzem estratégias que constroem autoridades e saberes reconhecidos, posto que desautorizam outras práticas encaradas como desviantes, sendo assim menosprezadas ou silenciadas. Essas disputas simbólicas se constituem em "lutas de representações" (Chartier, 1991), tão importantes quanto as lutas econômicas. 
Para acessar e interpretar essas representações, sugerimos aqui que o corpo, como objeto da história, oferece ao pesquisador a possibilidade de problematizar o cotidiano por meio de práticas que envolvem seus cuidados.

Na esteira dessa agenda de pesquisa, o corpo saudável, o educado, o doente, o belo, o gordo e o morto foram temas recorrentes nas historiografias francesa e brasileira. Entretanto, o corpo velho foi pouco explorado como categoria de análise no Brasil, com exceção dos estudos antropológicos, sobretudo quando o analisamos mediante uma modernidade que se esboçava nas cidades brasileiras.

Para Anthony Giddens (1991), a modernidade pode ser caracterizada pela constituição de instituições profundamente ligadas à confiança por parte dos indivíduos em "sistemas abstratos", em outras palavras, confiança em conhecimentos especializados e disseminados por peritos que se contrapõem à tradição. Entretanto, ainda segundo Giddens, não podemos vislumbrar a modernidade em uma concepção histórica evolucionista. Por isso, compreendemos que é preciso desconstruir essa perspectiva linear, em que a história é vista como uma unidade, e percebê-la em suas contradições, já que os conhecimentos especializados são reapropriados pelos indivíduos no cotidiano em diferentes espaços e temporalidades.

Dessa forma, em contextos citadinos no Brasil, a modernidade teria características específicas, em uma conjuntura de "modernização por tentativas" (Le Goff, 2013), quando não há uma relação equilibrada entre modernidade e tradição. A "modernização por tentativas" procura conciliar o moderno e o antigo por meio de uma gama de estratégias que, no entanto, não consegue estabelecer um equilíbrio. Gera apenas tentativas parciais e contraditórias de modernização. De acordo com Jacques Le Goff, em termos gerais, as sociedades podem se distinguir perante três exemplos de modernização: (a) "por tentativas", como explicamos; (b) "modernização equilibrada", na qual a penetração do moderno em relação aos valores antigos estabelece maior conciliação, exemplificada pelo autor pela sociedade japonesa; e (c) "modernização conflitual", que ocorre em sociedades que possuem graves conflitos gerados pela oposição entre o moderno e o antigo. A despeito dessas diferentes formas de modernização, concordamos com a tese do historiador Peter Burke (2010), que defende a inexistência de sociedades modernas nas quais as culturas sejam homogêneas ou puras, pois todas elas seriam impregnadas de inevitáveis "empréstimos culturais". Assim, representações e práticas que se originam num espaço migram para outros e, em um novo espaço, ganham novos contornos. A especificidade de uma modernidade brasileira residiria, contudo, como alude o antropólogo Ruben Oliven (2001, p.4), em uma rica dinâmica cultural capaz "de digerir criativamente o que vem de fora, reelaborá-lo e darlhe um cunho próprio que o transforma em algo diferente e novo". Por isso, perguntamos como, em cidades brasileiras, em um contexto de "modernização por tentativas", seriam constituídas as representações da velhice.

No Brasil, ainda que a confiança na modernidade sofresse resistência, como o desejo no campo cultural de uma representação mais genuína de "brasilidade" ancorada na mestiçagem, ou na imposição de uma modernização por meio de métodos e políticas conservadoras (Martinho, 2010), havia, por parte de alguns grupos sociais, a intenção de valorizar determinadas representações e práticas caracterizadas por uma modernidade 
bastante sólida em seus princípios de racionalidade da vida. Na década de 1930, esses grupos, compostos por médicos, intelectuais, educadores e cronistas, imaginavam uma modernidade brasileira similar à europeia.

Novas práticas que levavam aos prazeres individuais, ao conforto, aos divertimentos, e que, no caso brasileiro, estavam mais restritas a determinadas parcelas da população, conduziam as cidades para uma modernização particular. As mudanças pretendidas orbitavam entre educação, saúde e urbanização, e ao mesmo tempo evidenciavam maneiras de ser, de se portar ou, contrariamente, de resistir às representações e práticas voltadas para os corpos. De maneira mais específica, ao delimitarmos nosso olhar, estudamos as representações que emergiam das formas de envelhecer e ser velho nos espaços urbanos de grandes cidades brasileiras, como São Paulo e Rio de Janeiro. Em relação ao recorte temporal, interessou-nos em particular a década de 1930, que, no Brasil, se não representou as primeiras iniciativas de uma aproximação com os princípios da modernidade, possibilitou a análise de um período conflituoso, no qual o anúncio do moderno, paradoxalmente, era imposto por uma elite tradicional e autoritária (Martinho, 2010). Partimos do pressuposto de que teriam ocorrido "lutas de representações" (Chartier, 2002) no campo cultural, pois evidenciamos diferentes posturas perante os preceitos seculares da modernidade, tanto em uma perspectiva de adesão quanto se apropriando ou resistindo à racionalidade moderna. Enfim, as representações transitavam entre a tradição e a modernidade, sem se opor diametralmente, mas imbricando-se, constituindo os modos legítimos de envelhecer. Assim, nas cidades, como São Paulo e Rio de Janeiro, o Estado, por meio de políticas públicas de aposentadoria, urbanização, educação e saúde (Hochman, 2005), e também um mercado privado de técnicas, tecnologias e produtos estabeleceram representações diferenciadas sobre o corpo, e por conseguinte sobre os corpos velhos.

Traçados os caminhos, interrogamos as fontes acerca de como a velhice era representada em um projeto moderno voltado para os corpos em cidades brasileiras na década de 1930 .

Para isso, em termos metodológicos, realizamos uma pesquisa documental que encontrou 38 documentos datados entre 1930 e 1939. Esse corpo documental foi formado pelas seguintes fontes: (a) periódicos médicos, ${ }^{1}$ delimitados por sete documentos analisados, que puderam indiciar representações sobre a velhice por parte da produção científica brasileira; (b) os grandes jornais ${ }^{2}$ e revistas, publicados nas cidades de São Paulo e do Rio de Janeiro. Destas últimas fontes foram analisados 16 documentos provenientes de jornais cariocas, com destaque para o Jornal do Brasil e O Jornal. Em relação aos jornais paulistanos, foram 15 documentos, oriundos principalmente do Correio Paulistano. As fontes jornalísticas utilizadas na pesquisa tinham posições políticas características de uma grande imprensa mercantil, identificada com diferentes interesses, às vezes de cunho liberal, outras de cunho autoritário. Em outras palavras, como explica a historiadora da imprensa Maria Capelato $(1989,1992)$, essa "grande imprensa", produzida por empresas mais estruturadas, com novos maquinários e tecnologias, defendia um projeto editorial liberal que se apresentava como "imparcial", como representante da opinião pública, sendo seus jornalistas os verdadeiros "intérpretes das luzes". Ao mesmo tempo, oscilava entre a defesa das liberdades e o exercício de uma vox domini que aludia à repressão aos comunistas (Capelato, 1992; Barbosa, 2007). Além da linha editorial, a escolha dessas fontes se justifica também a partir do maior alcance dessas 
publicações em relação a públicos de diferentes extratos sociais e campos profissionais. Sendo assim, esses veículos se tornaram suporte na construção da visibilidade de inúmeras práticas culturais (Cruz, 2000).

Posteriormente, a partir do estudo das fontes, a análise foi organizada em dois eixos que deram especificidade aos documentos: no primeiro, a partir das fontes jornalísticas, argumentamos a constituição de uma educação não escolarizada, centrada no comportamento virtuoso para a administração da velhice; no segundo, a partir dos discursos dos médicos, a análise recai sobre o corpo e os tratamentos para vencer a velhice mediante apropriações de diferentes atores.

\section{Educar o corpo para administrar a velhice conforme a imprensa jornalística das principais cidades brasileiras}

Em um primeiro momento, poderíamos pensar que a modernização das cidades de São Paulo e do Rio de Janeiro promoveu mudanças de forma homogênea na vida de grandes parcelas de sua população. Ao percorrermos as fontes, contudo, perceberemos diferentes formas de representar a velhice e, concomitantemente, aceitar, contrariar e se apropriar dos modos de envelhecer na modernidade.

Na década de 1930, múltiplas formas de representar os corpos velhos começavam a ser anunciadas nos jornais. Uma delas era constante: a caracterização da velhice como solidão, tristeza e medo. Nesse caso, a velhice era representada de maneira dolorosa, com os velhos sendo isolados, e algumas vezes excluídos, de uma participação social efetiva, com a velhice trazendo consigo a doença, de forma análoga à descrita por Norbert Elias (2001) em $A$ solidão dos moribundos. Entretanto, havia também certo otimismo em relação ao envelhecer. Embora em manifestações menos frequentes, era possível ler nos jornais que a velhice era apenas uma fase da vida, com seus infortúnios mas também suas belezas. Nascia, naquele momento, uma representação, comum atualmente, de que a velhice não significava o fim e a morte, mas uma nova maneira de viver com seus corpos. Nesse caso, essa representação era mais condizente com o otimismo proveniente das realizações da ciência no início do século XX, com a longevidade sendo uma conquista alcançada pelos indivíduos mediante as prescrições médicas. Celia Cerviño escreveu no Jornal do Brasil, em 1939:

É assim a vida humana. No horizonte da vida surge a claridade da manhã: é o homem que nasce ... Passa a infância. Chega a mocidade envolta em luzes ... Nenhuma nuvem lhe tolda o céu da existência ... Mas a mocidade é tal a flor: nasce e morre depressa. Os olhos dos homens perdem então o brilho da juventude. Suas faces perdem o frescor da mocidade. É a velhice que chega ... Mas, também como a noite, não é menos bela esta quadra da vida: se em meio às luzes da juventude havia o dourado do sol, em meio à escuridão da velhice há o cintilar das estrelas, há a claridade do luar... (Cerviño, 5 fev. 1939, p.1).

No entanto, eram mais frequentes nos jornais as representações da velhice como um processo de decadência. Eram constantes as comparações entre corpos velhos e flores sem pétalas, árvores sem frutos ou com o inverno. Assim, a representação nessas crônicas enaltecia a juventude e condenava a velhice ao sentimento de saudade. O medo da morte 
e do esquecimento era patente. Em 1931, uma prosa assinada simplesmente pelo nome Magali foi publicada em O Jornal. Nas suas palavras:

Mocidade - rosas

Velhice - espinhos

Na mocidade a vida se afigura um paraíso azul. As flores tremem em divinais anseios, e tu caminhas sorridente pela estrada que se abre em risos e luz. Há saúde em teu corpo e sonhos no pensamento. Ha vibrações sonoras e cantos no teu peito.

Mas os dias passam, a Primavera vai findando. Morrem as rosas, caem as pétalas, e só ficam espinhos.

Tudo que te cerca é triste. É o inverno que chega ... Começam os gelos nas estradas e trevas no teu ser ... Os caminhos ficam brancos. Flocos de neve cobrem o solo. Que frio! Murmuras ... A luz se apaga lentamente e os sonhos se desvanecem. Nem uma só estrela brilha no teu céu; Voltas procurando o caminho percorrido: está tudo sombrio. Sonhaste e nada conseguiste, plantaste e nada colheste ...

Mas o frio aumenta e cais finalmente, desamparado, só, na grande solidão do túmulo que te espera... (Magali, 22 mar. 1931, p.3).

Para esses cronistas, a velhice representava a morte anunciada, a falta de saúde e a solidão. De forma alguma havia esperança, muito menos confiança na ciência médica no sentido de evitar ou amenizar tanto sofrimento. Havia apenas o sentimento de tristeza. Para o cronista Benjamin Costallat, em texto publicado no Jornal do Brasil, atingir a velhice era um heroísmo. Em seus termos:

A velhice já é a tristeza ... Matou-se. Depois de ter resistido até os oitenta anos. Resistiu muito. Não haverá, às vezes, mais heroísmo em resistir às tentações da paz que a morte promete do que resistir aos homens, aos inimigos e aos exércitos?

Um guarda noturno vivendo até os oitenta anos não será mais digno de glória do que um general resistindo até o último cartucho na mais heroica e terrível das batalhas? O supremo heroísmo é viver! (Costallat, 14 set. 1934, p.5).

O cronista não parece nada otimista em relação aos confortos da modernidade urbana. Viver era duro, morrer era ter paz, ficar velho era prova de resistência e heroísmo, sobretudo se fosse um trabalhador. É preciso sublinhar que a década de 1930 foi um período de reinvindicações das classes trabalhadoras no campo político, o que também motivou a organização de um sistema previdenciário no país. Em um tempo no qual o direito à aposentadoria começa a se institucionalizar, a representação da velhice como uma situação vulnerável e merecedora de assistência teve um papel importante no reconhecimento da aposentadoria como direito social, principalmente das classes trabalhadoras (Simões, 2000). Como já apontado, havia contradições entre a estruturação das aposentadorias e o papel do Estado no controle de movimentos operários. Entretanto, naquele momento, sem a possibilidade da aposentadoria, aquele trabalhador, o guarda noturno, estava impedido de usufruir desse direito, pois naquele cotidiano de trabalhador velho e pobre, aludia o cronista, o suicídio era uma saída digna.

Por isso, a metáfora do corpo humano como uma árvore sem frutos e folhas era óbvia, e a literatura acessada pelos jornais na forma de crônicas e contos contribuía para essa representação (Campos, 24 set. 1931). 
Para aqueles cronistas, a velhice não chegava repentinamente, mas de forma lenta, embora os sinais fossem claros. Desse modo, as possibilidades de decadência do corpo ao longo dos anos repercutiam na imprensa, e a pergunta que incidia sobre o medo da velhice era quando a decadência se iniciava. Quando homens e mulheres começavam a envelhecer? Os saberes autorizados a dar essas respostas residiam nas proposições médicas. A imprensa, por sua vez, desejava torná-los acessíveis, comunicando aos leitores a partir dos especialistas, dos médicos. Enfim, os saberes autorizados em uma "luta de representações" têm o poder de imposição de uma verdade. Assim, a informação jornalística era também considerada aceita e autorizada, pois era respaldada pela ciência. Contudo, os jornalistas tinham que conviver com a multiplicidade de informações desconexas e contraditórias provenientes dos cientistas. Em O Malho, Aurelio Pinheiro problematizava:

São incontáveis as teorias, os cálculos, as afirmativas de psicólogos e biologistas determinando a época precisa, a última etapa, a fronteira da existência onde a força mental atinge a sua magnífica plenitude e onde começa a penumbra melancólica da decadência, do declínio, da desoladora ruína.

Para alguns essa fronteira está fixada nos trinta anos, fim de mocidade e princípio de madureza; para outros, essa transição psicobiológica surge aos quarenta; e agora, para um professor da América do Norte que resolveu dedicar-se a essa tarefa de controle, o limite da máxima atividade mental se estende até os quarenta e sete e meio anos da vida (Pinheiro, 12 mar. 1936, p.33).

Todo o pessimismo na representação da velhice residia também nos desejos e nas saudades em relação à juventude. Portanto, a mocidade era um vocábulo recorrente nas representações da velhice, pois sua dicotomia era rígida, mesmo com todas as contradições da ciência médica a esse respeito. No campo cultural, muitas vezes a velhice era concebida de forma ligeira e simplificada como oposição à juventude. Ou se era velho, ou se era jovem. Mesmo no contexto das maiores cidades brasileiras, a crença na ciência, na medicina e nos confortos da modernidade convivia com sentimentos de impotência diante da velhice que significavam, muitas vezes, apenas a proximidade da morte. Não havia, nessa representação sobre a velhice, esperança em uma ciência que fosse capaz de controlar a natureza e rejuvenescer os corpos. A velhice era simplesmente a saudade da juventude (Simões, 8 jan. 1939).

Contudo, nos mesmos espaços e épocas que pareciam silenciar em relação às lutas da ciência contra a velhice, havia também a representação de uma moralidade moderna que criticava o comportamento tradicional dos velhos no campo da cultura. Revistas dedicadas às mulheres evidenciavam modos de ser e viver que estavam em oposição à ética vivida pelas mulheres velhas. Diante disso, ser uma mulher velha poderia também significar estar atrasada no tempo. A mulher moderna era representada como jovem, ativa e livre, já as mulheres velhas estavam, para a conhecida colunista carioca Crhysânteme, fora daquele tempo. Em artigo publicado na revista $A$ Vida Doméstica, em 1931:

Na sua larga cadeira de palha, forrada de coxins de chitão, dona Joanna, com as mãos cruzadas sobre o abdômen volumoso de anciã, mirava a neta que, esbelta, aureolada de mocidade em flor, dançava, sozinha, ao som da ortofônica, entoando um fox-trot. Com uma sua saia curta que adejava aos seus menores movimentos, como largas asas 
de borboleta, Clarinha, igualmente com os seus cabelos curtos, os seus braços nus, a boca carmesim, lembrava uma boneca nova, tirada recentemente da caixa. Clarinha manifestava-se moderna, feminista, libertada dos princípios que, durante toda a vida de dona Joanna, tinham sido sempre a base de seu proceder. E, quando levada ao auge da surpresa, a veneranda anciã ousava um protesto, era de fazer sorrir a resposta da criança: Ora, vovó, isso era no seu tempo! (Chrysantheme, 1 maio 1931, p.63).

Naquele momento, as revistas dedicadas às mulheres exaltavam a vida moderna. Desse modo, havia o incentivo ao consumo de novos eletrodomésticos, novas músicas, novas roupas e danças, novos modos de ser e agir. Ao mesmo tempo, reivindicavam a liberdade para as mulheres das classes média e alta e convidavam as leitoras para um mundo social, onde as formas de ser mulher estavam ancoradas em uma pedagogia da beleza (Campos, 2015). Naquela vida moderna, essas representações operavam sobre os desejos de liberdade, conquista e realização em uma perspectiva individual.

Entretanto, como descreve Denise Sant'Anna (2014), o mundo da propaganda ainda era distante do cotidiano das mulheres brasileiras no período, pois eram constantemente impedidas e criticadas ao se dedicarem a determinadas extravagâncias, leiam-se cuidados com o corpo. Por outro lado, quando a imprensa e suas propagandas investiam nas imagens de beleza e juventude, a velhice feminina era relegada ao esquecimento, sendo substituída pela necessidade compulsória de juventude. A antropóloga Guita Debert (2014) lembra que, longe de uma interpretação que coloca as mulheres como vítimas da indústria da beleza, há a necessidade de ressaltar que a publicidade crescente dessa indústria ao longo do século $\mathrm{XX}$, aqui evidenciada em um período inicial, contribuiu para produzir representações sobre pretensos modos corretos de viver dos "jovens de idade avançada" para reparar as marcas da velhice. Dessa maneira, a projeção da juventude nos corpos velhos, assim como a negação do envelhecimento progressivo, impediria a representação de uma estética própria da velhice (Debert, 2014).

Paralelamente, os cientistas observaram a oportunidade de promover suas próprias representações da velhice, aquelas em que era possível, por meio da ciência médica, adiar ou reverter o processo de envelhecer. Novas técnicas acessíveis a uma parcela ainda restrita de mulheres inauguravam um dos mercados de consumo mais promissores ao longo do século XX, o mercado dos corpos belos (Sant'Anna, 2014), que era representado pela projeção da juventude nos corpos, incluídos os dos velhos. Em 1939, no Jornal do Brasil, a então novidade para os velhos era o rejuvenescimento ao alcance da ciência médica, o que conhecemos hoje como cirurgia plástica, aliada a toda uma rede serviços estéticos:

Certa ocasião, travamos conhecimento com uma senhora de uns sessenta anos, que se havia submetido a uma intervenção cirúrgica, com o fim de eliminar as rugas existentes no seu rosto ... enfim, o rosto que o cirurgião havia 'criado' era o de uma mulher de uns vinte anos. $\mathrm{O}$ aspecto, porém, que essa senhora oferecia, era quase o de um fantasma ... Resolveu, então, não desanimar, e sim ir para a frente, e desta maneira obteve, na realidade, a força de vontade indispensável para tal fim ... Esse esforço íntimo para conservar a aparência de juventude já é, em si, um sinal de vitalidade psíquica. A senhora em questão iniciou um rigoroso tratamento de beleza, sob a direção criteriosa de um hábil profissional. Tomava diariamente longas massagens no rosto e no corpo. Começou a empregar numerosos produtos próprios para reconstituir os tecidos flácidos 
da epiderme e para reativar a circulação do sangue. Passava, diariamente, horas a fio batendo a sua pele e trabalhando-a com os preparados revigorantes. Impregnava, por assim dizer, a sua epiderme com óleos e cremes gordurosos. Seguia dieta. Submetia-se, com disciplina férrea, à atividade física. Dava longos passeios e praticava, regularmente, a sua ginástica ... Esse é um exemplo de verdadeiro rejuvenescimento (Um exemplo..., 4 jun. 1939, p.3).

Nessas cidades brasileiras, além dos serviços pouco acessíveis à maior parte da população e das críticas e preconceitos proferidos em relação aos homens e mulheres que se dedicavam aos seus próprios corpos, taxados como elite mundana, excêntricos, malandros, homossexuais ou prostitutas (Sant'Anna, 2014), havia, paradoxalmente, uma intensa campanha, em nome de uma ampliação desse mercado dos desejos de juventude, que reeducava os olhares sobre a velhice sob uma perspectiva de conquista pessoal, centrada nos corpos.

Por meio dessa educação não escolarizada, os indivíduos teriam maior controle sobre a velhice, desde que fossem condicionados por uma educação marcada pela disciplina, por uma dedicação ascética e perseverante para atingir os objetivos de fazer a juventude perdurar. O desejo de não envelhecer era bastante motivado pela imprensa. Jornais e revistas sustentados pela publicidade incentivavam, motivavam, justificavam o investimento nessa nova educação que ia além da juventude, dos cuidados com a infância, que estava agora presente em todas as fases da vida, por meio de massagens, ginásticas, cirurgias e tratamentos variados com suas promessas de rejuvenescimento. A velhice agora podia ser protelada, a longevidade como conquista individual movia os desejos das populações urbanas nos campos cultural e econômico, atingindo grupos sociais cada vez mais amplos conforme a modernidade era fomentada (Ariès, 2013).

Nesse sentido, discordamos de Allan Kellehear (2013), porque, para ele, a modernidade não explica as mudanças sobre as formas de viver a velhice e, mais especificamente, de administrar a morte. Ao contrário, essas mudanças seriam motivadas pelo predomínio dos valores da classe média nas sociedades industriais, como ansiedade, competição e individualismo, que fomentariam uma classe social de "hipocondríacos ansiosos que temem o envelhecimento e a morte como ninguém antes deles e se deixam atormentar pelo pensamento mágico e a superstição da salvação médica" (p.254). Discordamos do autor, pois ao observarmos as fontes brasileiras, percebemos que não foram as posições de classe que produziram, por parte dos indivíduos, representações variadas da velhice e da morte. Os cronistas e seus leitores, em sua maioria, podem ser considerados representantes das classes médias em São Paulo e no Rio de Janeiro, e mesmo comungando da mesma posição social, produziam representações muito diversas em relação à velhice. Ao ressaltar os valores da classe média como a categoria explicativa para as mudanças em relação aos modos de envelhecer e morrer, Kellehear (2013) deixa de observar e compreender que os papéis diferenciados de grupos sociais particulares, ainda que pertencentes à mesma classe média, contribuíram de formas específicas em relação aos modos de envelhecer na modernidade. Se não fosse assim, seria como interpretar que em apenas uma perspectiva estariam médicos, comerciantes, católicos e protestantes que, apesar de oriundos da mesma classe social, tiveram interesses diversos, e por vezes antagônicos, no que diz respeito à velhice. 
Porém, nosso argumento central tem outra direção; não nos interessa especificamente a morte, mas a velhice, pois a partir de suas representações compreenderemos práticas de diferentes grupos sociais em um processo de individualização das maneiras de viver a velhice na modernidade brasileira.

Corroborando a análise de Norbert Elias (1994), sem dúvida o controle dos comportamentos é uma característica estrutural das sociedades; o que havia de novo, no entanto, era a ênfase desse controle em uma perspectiva individual, ou seja, no autocontrole. No contexto das sociedades modernas, a partir do momento que os indivíduos abandonam a infância e a juventude, os impulsos são mais autocontrolados. Esse autocontrole, que antes era um controle social externo na infância e juventude, cria uma segunda natureza nos indivíduos, conforme suas experiências particulares (Elias, 1994).

Assim, se pensarmos no contexto urbano brasileiro, os investimentos da sociedade moderna nos corpos são apropriados no campo dinâmico da cultura pelos indivíduos. Isso não significa uma oposição entre os valores da sociedade e do indivíduo; para Elias (1994), é justamente o contrário; seria a "estrutura social da personalidade" que conforma um habitus de longa duração, não havendo mais sentido, portanto, na separação entre o coletivo e o individual. Por isso, o que podemos compreender é que as representações científicas deslocaram a responsabilidade da administração da velhice para cada indivíduo, a partir dos exemplos de boa conduta, virtude e cuidados com o corpo. O que, no caso, não seria uma particularidade brasileira, já que o estudo de Viet (2012) chega à mesma interpretação no contexto dos EUA em um período similar (1900-1930).

Assim, o que observamos nessas cidades brasileiras na década de 1930 seria apenas o início de uma educação que se consolidaria ao longo do século XX, que ia além da escolarização da infância e da juventude, uma educação não escolarizada centrada no comportamento virtuoso para a administração da velhice, promovendo uma responsabilização dos indivíduos. Nesse sentido, a conquista da longevidade seria difundida como um modo autônomo de viver a velhice com saúde. A sociedade e o Estado poderiam ter suas responsabilidades reduzidas em relação à velhice. Contudo, ao longo século XX, houve também um aumento da expectativa de vida das populações, o que promoveu o crescimento de demandas sociais em relação a um "regime de cuidados" para os idosos, gerando novos desafios e lutas políticas no âmbito das sociedades modernas (Groisman, 2015). Além disso, a maneira como esses brasileiros urbanos receberam essas orientações racionais na década de 1930 foi peculiar e difusa, pois correspondia apenas aos marcos iniciais de um processo, em que uma modernidade contraditória, em meio às "lutas de representação", promovia disputas de poder no campo cultural sobre a determinação dos melhores modos de viver a velhice.

Tratava-se de vislumbrar, como explica a antropóloga Guita Debert (2004), ao mesmo tempo, uma "institucionalização do curso da vida" mediante variadas apropriações que tornaram a idade uma dimensão fundamental na organização da vida social. Coube-nos, nesse sentido, em uma perspectiva histórica, observar as apropriações entre as representações sobre a velhice por parte da ciência em relação às representações provenientes da publicidade e dos cronistas, tendo como fontes a grande imprensa das maiores cidades brasileiras. 


\section{Medicina, ciência, publicidade e suas representações sobre a velhice em cidades brasileiras na década de 1930}

A ciência moderna no início do século XX, com o advento da gerontologia, começava a fomentar a conquista da longevidade como mais um avanço tecnológico das sociedades modernas que estaria ao alcance dos indivíduos (Katz, 1998). Se pudermos interpretar que a longevidade suscitava o interesse de muitas pessoas em uma sociedade moderna, também é verossímil que a modernidade brasileira, mediante suas contradições pautadas nos interesses e nas desigualdades entre grupos e classes sociais, se apropriasse de maneira particular de práticas avalizadas pelos cientistas e voltadas para os modos considerados legítimos de envelhecer. Assim, mesmo diante da secularização dos corpos e da medicalização da vida, também havia apropriações dos saberes autorizados, manifestadas em um comércio bastante movimentado de produtos duvidosos, porém acessíveis a uma população mais ampla, que, sem muitas informações, consumia os mais variados "remédios" para evitar a velhice.

A crença na racionalidade da ciência não afetava as populações de forma homogênea, pois as teses científicas eram, em alguns casos, contrariadas pela tradição católica ou até mesmo desacreditadas por parte considerável da população, atingida cotidianamente por normas impostas pelas políticas públicas de governos e sanitaristas. Contudo, também é importante ressaltar que as representações modernas da ciência, mesmo sem essa homogeneidade, influenciavam novos comportamentos nas populações urbanas, incutindo hábitos higiênicos que afetavam as moradias, fábricas e escolas.

Mesmo impactadas pelo progresso científico e pelas inovações nos tratamentos e descobertas relacionados à velhice, as populações urbanas mais amplas não tinham acesso a uma gama bastante diversa de serviços profissionais especializados em saúde para administrar a velhice. Apesar dessas desigualdades, surgiam cirurgias e tratamentos mais avançados e dispendiosos que prometiam mais tempo de juventude. Protelar a velhice e manter possível os traços da juventude também se afirmavam como desejos de consumo. Entretanto, quando se falava do envelhecer, com novas formas de viver a velhice sendo valorizadas em detrimento de outras, não havia equivalente apelo público de educação das massas. O envelhecer não tinha ainda a mesma atenção do Estado em termos de políticas públicas, com exceção do incremento da previdência social, mas o comércio dava centralidade à velhice, ou melhor, às formas de evitá-la por meio de um novo mercado de produtos e serviços especializados dirigidos aos desejos dos indivíduos. Afinal, a velhice administrada estava centrada em uma dimensão individual que, diferentemente da educação escolarizada, não era uma prerrogativa dos governos, pois era tida como uma conquista pessoal.

Sem a atenção das políticas públicas nem reivindicada como fomentadora da identidade brasileira, a velhice administrada promoveu um mercado de produtos e serviços que passam a ser ofertados a estratos sociais mais amplos, interessados nas promessas do rejuvenescimento. Com isso, uma gama de produtos é propagandeada nos jornais, sendo que muitos eram falsificações evidentes. Nesse cenário, os anúncios tinham o mesmo objetivo: vender juventude, protelar a velhice e rejuvenescer. Como estratégia, as propagandas desses 
produtos apelavam para o reconhecimento da ciência como discurso legitimador. Em 1936, um artigo no jornal Correio Paulistano, intitulado "Velhice é moléstia", anunciava:

'PEROLAS TITUS' é o remédio seguro para o mal da velhice. No Departamento de Produtos Científicos, Matriz, à avenida Rio Branco, 173, $2^{\circ}$ andar, Rio de Janeiro, e Filial, à rua de São Bento, 49, $2^{\circ}$ andar, em São Paulo, distribui-se ampla literatura a respeito, enviando-se também pelo correio. Para informações existem pessoas especializadas à disposição (Velhice..., 3 set. 1936, p.7).

Esses produtos comerciais atendiam aos desejos das pessoas que estavam impactadas pelas descobertas recentes da ciência e que, por conta da chancela dos "cientistas", estavam dispostas a consumi-los. Porém, boa parte deles só tinha respaldo da ciência nos próprios anúncios. Consideramos, portanto, que a falsidade dos resultados desses produtos e suas promessas estapafúrdias conquistavam, mesmo assim, um mercado consumidor, dada a frequência dos anúncios nos jornais. Esse mercado só podia ser formado a partir de dois pressupostos: primeiramente, pela constituição de grupos sociais que desejavam o capital simbólico da juventude; e pela crença na ciência como detentora da verdade, com poder sobre a natureza dos corpos. Por isso era fundamental que as propagandas estivessem atentas a qualquer pesquisa recente que envolvesse a velhice. Os periódicos médicos relatavam as inovações e o desenvolvimento de técnicas de cirurgias estéticas. Não seria vaidade, era necessidade, nos termos do cirurgião Pires Rebelo, na Imprensa Médica, em 1930:

Numa moderna clínica de beleza, ao lado dos processos já conhecidos e bem divulgados, existem outros novos e de resultados eficazes no que diz respeito à estética. Queremos referir-nos às partes elétrica e operatória, sem dúvida as que mais sucesso trazem às questões do embelezamento...

Não só na Europa como na América do Norte, vários escritos sobre o importante assunto da cirurgia reparadora têm aparecido, todos eles assinados pelos mais notáveis cirurgiões. Aqui no nosso país, esse novo ramo da cirurgia ainda se encontra em início, mas em pouco tempo terá, como no estrangeiro, um grande desenvolvimento ... É preciso ficar bem claro não se tratar de vaidade um caso em que o cirurgião esteta tenha que intervir. Muitas profissões requerem rostos jovens, desenrugados. É unicamente uma questão de necessidade (Rebelo, 1930, p.742-743).

Embora as cirurgias fossem restritas às elites, elas também atuavam sobre os desejos de distinção, criando um mercado de produtos que, mesmo sem a mesma eficácia, eram mais acessíveis. Em um anúncio do Correio Paulistano, um simples comprimido era a solução das rugas, ainda que o próprio texto já alertasse sobre seus efeitos lentos:

As drágeas W-5, que contêm os 'corpos de imunidade' descobertos pelo Dr. Kapp, são o específico da reconstrução da pele; produzem efeito lento, porém seguro. No Departamento de Produtos Científicos, Matriz, à avenida Rio Branco, 173, $2^{\circ}$ andar, Rio de Janeiro e Filial, à rua de São Bento, 49, $2^{\circ}$ andar, em São Paulo (W-5, 29 set. 1934, p.4).

Apesar dessa apropriação dos discursos médicos em relação à velhice, uma gama considerável de importantes laboratórios internacionais, bem como pesquisadores renomados na Europa e nos EUA, perseguia este problema de pesquisa: como protelar a velhice ou até mesmo inverter o processo, ocasionando um rejuvenescimento? Um dos 
primeiros pesquisadores a ganhar destaque na imprensa de São Paulo e do Rio de Janeiro foi o médico russo Serge Voronnoff. O historiador Thomas Cole (1993) descreve Voronoff como o primeiro pesquisador a trabalhar com transplante de glândulas hormonais, o que, para o russo, seria a solução para evitar a velhice. Serge Voronoff (1866-1951) foi diretor da cirurgia experimental no Laboratório de Fisiologia do Collège de France (Cole, 1993). Em entrevista na Itália, publicada em A Gazeta, em 1931, Voronoff explicava:

Como poderemos viver 140 anos? Voronoff mostra o que se pode fazer para prolongar a vida, sob as condições da atual existência.

Grimaldi (Itália) - fevereiro - Agência Brasileira. Serge Voronoff, o mágico do rejuvenescimento, pretende algum dia rejuvenescer-se a si próprio. Apontando certa vez para uma gaiola, onde se achavam enormes chimpanzés, o sábio disse: 'Aquele é o Theodoro, está reservado para mim ... quando precisar de suas glândulas' ... É, portanto, necessário descobrir a maneira de não ser morto e preservar a energia do corpo, permitindo-lhe resistir a seus inimigos ...

Consequentemente, acredito que quando os homens tiverem à sua disposição meios poderosos de prolongar a vida, será absurdo deixarem de o fazer, o que equivaleria a andar de carro à tração animal na época de estrada de ferro, do automóvel e do aeroplano (Como poderemos..., 11 mar. 1931, p.3).

O otimismo de Voronoff estava ancorado nas conquistas da modernidade, pois se a ciência e a tecnologia tinham obtido avanços, por exemplo em relação aos meios de transporte, por que não teria êxito em prolongar a vida? Como ele mesmo dá a entender em seu depoimento, ele não estava sozinho, pois havia um grupo de pesquisadores que perseguia os mesmos objetivos desde o século XIX e início do século XX, como o prestigiado médico Charles-Édouard Brown-Séquard (1817-1894), sucessor de Claude Bernard na cadeira de medicina experimental no Collège de France; e Elie Metchnikoff (1845-1916), médico russo que, em 1888, assumiu uma cadeira no Instituto Pasteur e, por conta de suas pesquisas no campo da imunologia, conquistou o prêmio Nobel de medicina em 1908. Havia também pesquisadores contemporâneos de Voronoff, como Alexis Carrel (1873-1944), médico francês, pesquisador no Instituto Rockefeller, agraciado com o prêmio Nobel de medicina em 1912, com um trabalho sobre cultura de células e cirurgia; e Eugene Steinach (1861-1944), fisiologista austríaco, diretor do Instituto Biológico de Viena (Cole, 1993). Ou seja, a questão do envelhecimento atraía os olhares de pesquisadores renomados que contribuíam para uma representação da velhice como doença que poderia ser controlada. Se a velhice era uma doença, seria preciso descobrir as causas, o tratamento e a cura. Sem dúvida um problema intangível, pois como poderiam diferenciar uma velhice normal de outra, patológica? (Groisman, 2002). No entanto, é interessante observar como a imprensa brasileira representava a busca da cura da velhice e do rejuvenescimento ou ao menos de uma administração do envelhecimento.

Primeiramente, as notícias sobre as descobertas que envolviam o tema da velhice eram acompanhadas por propagandas. Essas pesquisas, ao despertar esperanças de rejuvenescimento, possibilitavam a exploração dos desejos de consumo de seus leitores, propiciando assim a constituição de um mercado de produtos duvidosos que atrelavam suas imagens à pesquisa científica. Por exemplo, após a divulgação das intenções de rejuvenescimento de Voronoff com 
enxertos hormonais e transplantes de glândulas na imprensa brasileira, anúncios proclamavam soluções mais simples e baratas que tinham a "anuência" de Voronoff, ou promoviam produtos propagandeados como mais sofisticados que as descobertas do pesquisador russo. Como exemplos, anúncios no Correio Paulistano, intitulados respectivamente "Sylvino P. Araujo: o Voronoff brasileiro" e "Enxertos glandulares?".

Porque o Dr. Sylvino Pacheco de Araujo, eminente médico brasileiro, como o grande cientista russo, também criou, com o seu maravilhoso preparado 'FLUXO-SEDATINA', o rejuvenescimento da mulher, fazendo desaparecer milagrosamente, em menos de 2 horas, as dores mensais, acalmando, regularizando e vitalizando os seus órgãos, facilitando os partos, sem dores, cujos perigos tanto aterrorizam a mulher (Sylvino..., 25 jul. 1930, p.13).

O doutor Sylvino Pacheco de Araújo era, na verdade, um farmacêutico mineiro (Almanak Laemmert, 1918) que se tornou médico apenas em 1930 (Almanak Laemmert, 1930), ano no qual é veiculado o anúncio. As publicidades de fórmulas mágicas tinham em comum a facilidade da administração oral de comprimidos (Enxertos..., 26 jun. 1935, p.14) e os custos reduzidos em relação aos difíceis tratamentos, ginásticas, massagens e cirurgias, bem mais custosos em termos de esforços e recursos financeiros.

Assim, as propagandas seduziam seus consumidores a partir de apropriações dos discursos médicos e das descobertas científicas, porém conforme os interesses de um comércio específico, um mercado de rejuvenescimento e suas fórmulas inventivas, que promoviam a divulgação de pesquisas científicas estrangeiras cujo objetivo era a conquista individual de uma administração da velhice. A esse mercado interessava a disseminação de representações modernas sobre os corpos velhos com o intuito de ampliar, em nome dos desejos individuais, o consumo.

Além dessas representações que atestam uma penetração, embora não homogênea, de uma medicina pautada em técnicas cirúrgicas, ginásticas, massagens e tratamentos estéticos, é preciso ressaltar que a centralidade nos corpos rejuvenescidos possibilitava aos médicos uma ampla visibilidade nos jornais, com o intuito de esclarecer os leitores sobre as novidades propagandeadas pelo mercado da administração da velhice.

Por exemplo, em 1936, o Correio Paulistano publica uma entrevista com um dos mais reconhecidos especialistas no assunto, o doutor Alexis Carrell, do Instituto Rockefeller, o maior centro de pesquisas médicas nos EUA. Carrell, com sua perspectiva eugênica, acreditava que a modernidade tinha substituído a seleção natural pela possibilidade de sobrevivência e reprodução de indivíduos genética e cronicamente doentes. Desse modo, a ciência deveria ter cautela ao pensar em prolongar a vida, sem antes possibilitar um envelhecer natural e saudável (Cole, 1993). Para Carrell, seria contraproducente ampliar a população de velhos sem que eles pudessem ser produtivos. Carrell perguntava: "Por que deveríamos adicionar mais anos à vida de pessoas que são infelizes, egoístas, estúpidas e inúteis?" (Cole, 1993, p.207).

Nesse momento, parte dos médicos e cientistas, como Elie Metchnikoff, representava a longevidade como uma conquista, em que a senilidade não impediria o indivíduo de viver a velhice com saúde e produtividade (Groisman, 2015). Alexis Carrell, ao contrário, 
compreendia que a longevidade não era uma conquista, pois ocasionaria um problema social e eugênico. Para ele, a longevidade promoveria um desequilíbrio entre as populações idosas e jovens, ampliando o contingente de populações improdutivas.

Embora, na década de 1930, o Brasil fosse um país de jovens, com mais de 29 milhões de habitantes entre 0 e 29 anos, o equivalente a 64,75\% da população (IBGE, 1939, 1946), os receios de Carrell sobre a conquista de maior longevidade eram pautados na discussão dos países mais ricos, e também consistiam em uma resposta a todo o entusiasmo que a publicidade e os jornais alardeavam a respeito do rejuvenescimento. Ao mesmo tempo, a grande imprensa das principais cidades brasileiras silenciava sobre as condições de vida dos velhos, sobretudo dos mais pobres.

Ainda acerca de Carrell, mesmo com os receios em relação à longevidade, ele também pesquisava a velhice a partir da biologia celular, tendo êxito em uma técnica que propiciou a preservação de uma cepa de células do coração de um galináceo em estado embrionário. Sendo uma das referências no assunto, era bastante crítico em relação aos métodos empregados por seus contemporâneos, como Serge Voronoff. Sem citar o nome do pesquisador russo, Carrell chama a técnica dele, a partir do transplante de glândulas de macacos, de tapeação. Dessa forma, ao ser perguntado como rejuvenescer e prolongar a vida, sentencia em entrevista ao jornal Correio Paulistano:

O princípio é simples. Leva a uma vida mais áspera, asceéica, pouco diferente da que levavam os homens primitivos. Leva ao único método de rejuvenescimento. Esses métodos de glândulas de macacos e outros são 'tapeações', diz ele. E o Dr. Carrell deve saber o que diz. 'As criaturas humanas deveriam poder viver por séculos', disse ele recentemente.

E nós devemos lembrar que as utopias de hoje são as realidades de amanhã. Nunca conquistaremos, entretanto, a morte, diz o Dr. Carrell, mas o rejuvenescimento poderá ser conseguido, embora ainda leve um século ou mais para ser descoberto o meio (Entrevista..., 1 out. 1936, p.16).

Da mesma forma, o médico Julio Cantala publicou vários artigos sobre descobertas científicas em jornais brasileiros, principalmente no Correio Paulistano e no Diário de Notícias, publicações de São Paulo e do Rio de Janeiro, respectivamente. Sobre o tema do rejuvenescimento, evidenciava todo o seu ceticismo em relação a essas pesquisas. Seu posicionamento nos explica o porquê de a imprensa médica especializada no Brasil dar pouca atenção ao assunto, já que a infância e a juventude eram temas muito mais recorrentes nos periódicos médicos do que os estudos sobre a velhice. Afinal, seus resultados eram muito mais tangíveis e adequados à perspectiva brasileira de um país representado como jovem. Desse modo, restava à grande imprensa relatar e divulgar o debate internacional a respeito dos estudos da velhice, com o intuito de satisfazer os apelos individuais de seus leitores. Em 1937, o doutor Cantala, no jornal Correio Paulistano, em artigo intitulado "A pedra filosofal e o elixir da longa vida", aludia:

A medicina e a higiene, lutando contra as doenças e prevenindo uma boa estabilidade fisiológica, eliminando o perigo constante das epidemias, estipulando normas racionais de trabalho e de vida social, têm baixado muito o índice de mortalidade nos países de civilização avançada. Em artigo recente, Jean Rostand afirma que a 
média de vida, computada em bloco, é atualmente de 50 anos, quando há meio século passado era de 33 aproximadamente. O rejuvenescimento, ou melhor, a prolongação da mocidade é, no entanto, questão bem mais complexa (Cantala, 8 abr. 1937, p.17).

Apesar do desinteresse dos melhores pesquisadores brasileiros, muito mais atentos à higiene da infância e ao controle de doenças tropicais, a grande imprensa continuava reforçando a representação da velhice como uma fase da vida que, no futuro próximo, viria a se tornar mais aprazível e mais bem administrada por conta da modernidade e das descobertas científicas. Nesse sentido, muitas notícias relatavam novas técnicas, oriundas da Europa e dos EUA, que tinham em comum o controle sobre o declínio físico ocasionado pela velhice.

Exemplos, como no artigo "O segredo da mocidade eterna", em que um inventor francês, Georgia Knap (1866-1946), diz ter descoberto o princípio do rejuvenescimento mas também não estar disposto a divulgá-lo (O segredo..., 16 jun. 1935). Faleceu, contudo, aos 80 anos. Na reportagem "O problema da longevidade humana", o pesquisador Paul Kouchakoff, que trabalhava em Nice, na França, e depois em um laboratório de bioquímica em Lausanne, na Suíça, defendia a ingestão restritiva de alimentos crus como fórmula de longevidade que poderia levar o homem aos 270 anos (O problema..., 9 ago. 1930). Até mesmo a imprensa de linha editorial comunista, como o periódico paulistano O Homem Livre, divulgava as últimas notícias sobre o estudo da velhice na Rússia. O artigo "Ciências, ofensiva contra a morte" atestava que ali estavam presentes as mesmas representações científicas de preservação da juventude. Sendo assim, é possível compreender que haveria, por parte dos operários, o mesmo interesse na administração da velhice. Nele, a figura do biofísico russo Petr Petrovich Lazarev (1878-1942) era o argumento de autoridade para defender a ideia de que a vida humana poderia ser prolongada. Em suas palavras: "A biofísica declara, portanto, segundo Lazarev, que a morte alcança o homem muito cedo, prematuramente, e que o organismo de um centenário poderia arcar ainda com cerca de oito décadas" (Ciências..., 27 maio 1933, p.3). Se um periódico comunista via com interesse o domínio sobre a natureza da velhice, o mesmo não ocorria com parcela dos católicos brasileiros, eles próprios provenientes das classes médias, mas contrários aos desejos de rejuvenescimento.

Como exemplo da crítica de católicos brasileiros, relatamos que, em 1932, o médico norte-americano Paul de Kruif (1890-1971) escreveu o livro Men against death, publicado no Brasil com o título A luta contra a morte. Nele o médico norte-americano descreve a trajetória das pesquisas sobre a velhice da segunda metade do século XIX até o início da década de 1930. A recepção de seu livro não causou maior alarde na imprensa brasileira, com exceção do artigo assinado pelo educador católico Amadeus Mendes, intitulado "Uma página de Paul de Kruif", em 1939:

O sr. Paul de Kruif, porém, não se preocupa em afastar do seu espírito a ideia de morte. Ao contrário: teima em acompanhar as pesquisas dos que procuram conseguir protelar a sua aparição, uma vez ser de todo impossível obter a sua exclusão ... 'O maior desejo do homem - diz ele - é a juventude eterna. De Merlin até Gagliostro, Brown-Sequard e Voronoff, charlatões e sábios tiveram o mesmo sonho e sofreram a mesma derrota. Ninguém descobriu o segredo supremo'. 
O elixir da longa vida! Quanta esperança longamente acariciada, desesperadoramente sonhada e, ao depois, cruelmente desfeita! Mas, afinal, o prolongamento da vida, mesmo sem o cortejo das tristezas e amarguras da velhice, trar-nos-ia a suspirada felicidade?

As sedutoras promessas das bem-aventuranças celestes que os bons e os santos predizem aos mortais ainda não lhes conseguiram anular o incoercível apego às atrações da vida terrena. O padre Manuel Bernardes naquela sua linguagem branda e castiça relembra as palavras do Espírito Santo, quando afirmava 'que a memória da morte é amargosa para aqueles a quem a possessão da vida é doce' (Mendes, 5 out. 1939, p.4).

A publicação do livro de Paul de Kruif não contrapunha a ética religiosa norte-americana. Thomas Cole (1993) explica que, da mesma forma que Max Weber observou em seu clássico A ética protestante e o espírito do capitalismo, uma lógica de interdependência entre religião e economia, também havia a mesma lógica relacional entre os propósitos dos reformadores da saúde pública e da ética religiosa puritana nos EUA. Ao estudar a história da velhice naquele país, Cole considera que algumas características do calvinismo e dos presbiterianos norte-americanos, como autocontrole e uma rígida disciplina moral, eram congruentes com os objetivos higienistas de autonomia e de governo de si. Essa convergência produzia naquele contexto uma "moralidade civilizada", que por sua vez enfatizava um controle físico dos desejos e dos impulsos dos corpos. Segundo o autor, no caso norte-americano, tanto os religiosos como os médicos e cientistas compreendiam esses investimentos na saúde dos corpos de maneira positiva desde o século XIX. Entretanto, no Brasil, não foi possível observar a mesma convergência. Na década de 1930, seria difícil compreender os católicos como um grupo coeso no que diz respeito aos cuidados com os corpos, já que, embora educadores católicos dessem importância e defendessem uma educação higiênica, outros, como Amadeus Mendes, paradoxalmente viam os investimentos da ciência em relação às estratégias de rejuvenescimento como uma supervalorização de uma ética dos corpos, da vida terrena, em detrimento da educação das almas. Alguns católicos brasileiros se opunham à modernização e às consequentes transformações no campo cultural. Um exemplo representativo seria a produção intelectual do católico Tristão de Athayde. No texto "A idade nova e a ação católica", publicado no periódico católico A Ordem, em 1935, Athayde critica o homem moderno, a ciência e as universidades, por percebê-los como catalisadores de uma crise moral. Em seus termos:

Nunca vimos, ao contrário, como hoje em dia, tanta despreocupação com o futuro, tanta agitação vazia, tanta febre de viver intensamente, de arrancar da vida terrena tudo o que ela possa dar. Nesse homem moderno - que no fundo não existe, pois há todas as espécies de homens modernos e o signo da diversidade em que vivemos se reflete, justamente, na multiplicidade infinita de temperamentos, de soluções, de pontos de vista, que fazem de nossa época um caos mais ou menos dourado de ciência ... Onde estamos, então? No fim da revolução burguesa ... tendo por ideal a liberdade absoluta, caracterizadas pelo predomínio da raça branca, pela industrialização do ocidente, pela religião da ciência e pela decadência do prestígio da religião, pela arte puramente estética, pelo culto da cultura, pelas viagens de recreio, pela libertação sexual do homem, o urbanismo generalizado, o triunfo das economias abertas e livres, as universidades em que tudo se ensina sem ordem nem hierarquia de valores, o feminismo etc. ... E o resultado foi o fenecimento de toda a cultura e de toda a vida (Athayde, 1935, p.104-105). 
Observamos, no entanto, a partir das fontes de jornais e revistas, que mesmo diante dessas contradições e das apropriações em uma modernidade brasileira, houve importante reiteração dos preceitos científicos em relação aos comportamentos considerados adequados para o cuidado dos corpos ou para a administração da velhice, atestada pela constituição de um mercado do rejuvenescimento.

\section{Considerações finais}

Nossa proposta nesta investigação foi interrogar as fontes sobre como a velhice era representada mediante um projeto moderno voltado para os corpos nas maiores cidades brasileiras na década de 1930. Na literatura internacional acerca da velhice, Pat Thane (2003) relata que tanto as pesquisas de história cultural como as de história social concordam sobre o fato de que a velhice como objeto da história permite a observação de múltiplas representações que variam no espaço e no tempo, sendo difícil encontrar homogeneidade. Já Norbert Elias (2001) argumenta a respeito de uma experiência cada vez mais solitária e individualizada da velhice nas sociedades modernas. Da mesma forma, Stephen Katz (1999) ressalta que o advento da velhice como objeto da ciência no início do século XX e a consolidação da gerontologia ao longo do mesmo século contribuíram para a representação de uma velhice como conquista individual, com suas imagens positivas. Assim, as práticas relacionadas ao envelhecer entendem essa representação como unívoca, restringindo a liberdade dos indivíduos mais velhos e impondo-lhes expectativas irrealistas. Entretanto, as representações negativas dos velhos também são produtoras de preconceitos, ao passo que ainda promovem uma imagem homogênea da velhice, sempre restrita à solidão e à doença (Katz, 1999).

Essas diferentes representações sobre a velhice já eram observadas nas principais cidades brasileiras na década de 1930; era o início de uma responsabilização dos indivíduos quanto à administração do envelhecer própria das sociedades modernas. Analisamos, entretanto, algumas particularidades da modernidade brasileira que propiciaram apropriações e resistências particulares em relação aos discursos científicos acerca da velhice.

Assim, mesmo diante de uma nação brasileira "imaginada" por parte de suas elites como uma comunidade próspera, urbana e moderna, no âmbito das grandes cidades, onde os discursos médicos podiam ser caracterizados por sua racionalização, havia outras representações da velhice reivindicadas por tradições religiosas das mesmas elites, gerando disputas por uma representação legítima da velhice. Nesse contexto, intelectuais católicos, como Amadeus Mendes e Tristão de Athayde, motivaram um julgamento moral sobre a modernidade e os desejos da vida terrena. Também observamos apropriações dos discursos científicos motivados pelo incremento de um comércio mais amplo e acessível que divulgava os avanços tecnológicos com o intuito de legitimar seus produtos duvidosos.

Essas particularidades evidenciam que as representações sobre a velhice eram concebidas mediante contradições culturais produzidas no contexto de uma modernidade brasileira. Em outras palavras, no contexto de cidades brasileiras afetadas por uma "modernização por tentativas", no caso, São Paulo e Rio de Janeiro. Não pretendemos aqui generalizar essas interpretações para todo o país, mas defender a tese de que as contradições da modernidade nessas cidades contribuíram para a existência de diferentes representações acerca da velhice. 
Seria essa tese que impediria uma descrição homogênea da velhice, mas que ao mesmo tempo atesta um considerável aumento do poder dos saberes científicos e médicos, em uma "luta de representações" quanto aos comportamentos considerados adequados em relação aos corpos nas principais cidades brasileiras na década de 1930.

\section{AGRADECIMENTO}

Este artigo é fruto de um projeto docente regular financiado pela Fundação de Amparo à Pesquisa do Estado de São Paulo (Fapesp), processo n.16/00617-6.

\section{NOTAS}

${ }^{1}$ Os documentos foram encontrados na Biblioteca da Faculdade de Medicina da Universidade de São Paulo (USP). É importante ressaltar que o tema da velhice não era frequente nessas fontes, e esses silêncios foram considerados na análise.

${ }^{2}$ A documentação dos jornais foi pesquisada nos acervos do Arquivo Público de São Paulo e da Hemeroteca Digital da Biblioteca Nacional.

\section{REFERÊNCIAS}

ALMANAK LAEMMERT.

Edição D86, v.1, p.466. 1930.

ALMANAK LAEMMERT.

Edição A74, v.2, p.3017. 1918.

ARIÈS, Phillipe.

O homem diante da morte. São Paulo: Edunesp. 2013.

ATHAYDE, Tristão de.

A idade nova e a ação católica. A Ordem, n.61, p.103-132. ago. 1935.

BARBOSA, Marialva.

História cultural da imprensa: Brasil, 1900-2000.

Rio de Janeiro: Mauad. 2007.

BURKE, Peter.

Hibridismo cultural. São Leopoldo: Editora

Unisinos. 2010.

CAMPOS, Humberto de.

Notas de um "diarista". O Jornal, p.4. 24 set. 1931.

CAMPOS, Raquel D.

A educação do corpo feminino no Correio da Manhã (1901-1974): magreza, bom gosto e envelhecimento. Cadernos Pagu, v.45, n.2, p.457478. 2015.

CANTALA, Julio.

A pedra filosofal e o elixir da longa vida: ciência e o mundo: revista das ciências. Correio Paulistano, p.17. 8 abr. 1937.

CAPELATO, Maria Helena.

O controle da opinião e os limites da liberdade: imprensa paulista (1920-1945). Revista Brasileira de História, v.12, n.23/24, p.55-75. 1992.
CAPELATO, Maria Helena.

Os arautos do liberalismo: imprensa paulista

(1921-1945). São Paulo: Brasiliense. 1989.

CERVIÑO, Celia.

Mocidade e velhice. Jornal do Brasil. Livro aberto às crianças, p.1. 5 fev. 1939.

CHARTIER, Roger.

A história cultural: entre práticas e representações. Lisboa: Difel. 2002.

CHARTIER, Roger.

O mundo como representação. Estudos Avançados, v.11, n.5, p.173-191. 1991.

CHRYSANTHEME.

A mocidade e a velhice. A Vida Doméstica: Revista do lar e da mulher, n.58, p.63. 1 maio 1931.

CIÊNCIAS...

Ciências, ofensiva contra a morte. O Homem Livre, p.3. 27 maio 1933.

COLE, Thomas R.

The journey of life: a cultural history of aging in America. Cambridge: Cambridge University Press. 1993.

COMO PODEREMOS...

Como poderemos viver 140 anos? A Gazeta, p.3. 11 mar. 1931.

COSTALLAT, Benjamin.

O supremo heroísmo. Jornal do Brasil, p.5. 14 set. 1934.

CRUZ, Heloísa de Faria.

São Paulo em papel e tinta: periodismo e vida urbana (1890-1915). São Paulo: Imprensa Oficial. 2000 . 
DEBERT, Guita Grin.

Velhice e tecnologias do rejuvenescimento. In: Goldenberg, Mirian. Corpo, envelhecimento e felicidade. Rio de Janeiro: José Olympio. p.65-82. 2014.

DEBERT, Guita Grin.

A antropologia e o estudo dos grupos e das categorias de idade. In: Barros, Myriam Moraes Lins de. Velhice ou terceira idade? Rio de Janeiro: FGV Editora. p.49-68. 2006.

DEBERT, Guita Grin.

A reinvenção da velhice. São Paulo: Edusp. 2004.

ELIAS, Norbert.

A solidão dos moribundos: envelhecer e morrer. Rio de Janeiro: Jorge Zahar. 2001.

ELIAS, Norbert.

A sociedade dos indivíduos. Rio de Janeiro: Jorge Zahar. 1994.

ENTREVISTA...

Entrevista com o Dr. Alexis Carrell, do Rockefeller Institute for Medical Research. A ciência e o mundo. Correio Paulistano, p.16. 1 out. 1936.

\section{ENXERTOS...}

Enxertos glandulares? O rejuvenescimento das pessoas de ambos os sexos. Correio Paulistano, p.14. 26 jun. 1935.

GIDDENS, Anthony.

As consequências da modernidade. São Paulo: Edunesp. 1991.

GROISMAN, Daniel.

O cuidado enquanto trabalho: envelhecimento, dependência e políticas para o bem-estar no Brasil. Tese (Doutorado em Serviço Social) Universidade Federal do Rio de Janeiro, Rio de Janeiro. 2015.

GROISMAN, Daniel.

A velhice, entre o normal e o patológico.

História, Ciências, Saúde - Manguinhos, v.9, n.1, p.61-78, 2002.

GROISMAN, Daniel.

Asilos e velhos: passado e presente. Estudos

Interdisciplinares de Envelhecimento, v.2, p.67-87. 1999.

HOCHMAN, Gilberto.

Reformas, instituições e políticas de saúde no Brasil (1930-1945). Educar em Revista, v.25, p.127141. 2005.

IBGE.

Instituto Brasileiro de Geografia e Estatística. Anuário Estatístico do Brasil. Rio de Janeiro: IBGE. 1946.
IBGE.

Instituto Brasileiro de Geografia e Estatística. Anuário Estatístico do Brasil. Rio de Janeiro: IBGE. 1939.

KATZ, Stephen.

Old age as lifestyle in an active society. Berkeley:

Occasional Papers Series. 1999.

KATZ, Stephen.

Disciplining old age: the formation of gerontological knowledge. Bulletin of the History of Medicine, v.72, n.3, p.594-595. 1998.

KELLEHEAR, Allan.

Uma história social do morrer. São Paulo: Edunesp. 2013.

LE GOFF, Jacques.

História e memória. Campinas: Editora da

Unicamp. 2013.

MAGALI.

A mocidade e a velhice. O Jornal, p.3. 22 mar. 1931.

MARTINHO, Francisco C.P.

Os corporativismos português e brasileiro: proximidades e distanciamentos entre a tradição e a modernidade. In: Reis, Daniel Aarão.

Tradições e modernidades. Rio de Janeiro: FGV Editora. 2010.

MENDES, Amadeus.

Uma página de Paul de Kruif. Correio Paulistano, p.4. 5 out. 1939 .

OLIVEN, Ruben G.

Cultura e modernidade no Brasil. São Paulo em Perspectiva, v.15, n.2, p.3-12. 2001.

O PROBLEMA...

O problema da longevidade humana: um sábio russo pretende tê-lo resolvido. Correio Paulistano, p.1. 9 ago. 1930 .

O SEGREDO...

O segredo da mocidade eterna. Correio

Paulistano, p.6. 16 jun. 1935.

PEIXOTO, Clarice.

Entre o estigma e a compaixão e os termos classificatórios: velho, velhote, idoso, terceira idade... In: Barros, Myriam Moraes Lins de. Velhice ou terceira idade? Rio de Janeiro: FGV Editora. p.69-84. 2006.

PINHEIRO, Aurelio.

O Malho, v.35, n.145, p.33. 12 mar. 1936.

REBELO, Pires.

A cirurgia estética e a eletricidade médica numa clínica de beleza. Imprensa Médica, p.742-743. 20 nov. 1930. 
SANT'ANNA, Denise B.

História da beleza no Brasil. São Paulo: Contexto. 2014.

SIMÕES, Júlio Assis.

Entre o lobby e as ruas: movimento dos aposentados a politização da aposentadoria. Tese (Doutorado em Ciências Sociais) - Universidade Estadual de Campinas, Campinas. 2000.

SIMÕES, Maria da Penha.

Mocidade e velhice. Jornal do Brasil. Caderno Livro aberto às crianças, p.1. 8 jan. 1939.

\section{SYLVINO..}

Sylvino P. Araujo: Voronoff brasileiro, a mulher não precisa de enxertos. Correio Paulistano, p.13. 25 jul. 1930.
THANE, Pat.

Social histories of old age and aging. Journal of Social History, fall, p.93-111. 2003.

UM EXEMPLO...

Um exemplo de rejuvenescimento. Jornal do Brasil. Caderno Segunda Seção, p.3. 4 jun. 1939.

VELHICE...

Velhice é moléstia. Correio Paulistano, p.7. 3 set. 1936.

VIET, Helen Zoe.

"Why do people die?" Rising life expectancy, aging, and personal responsibility. Journal of Social History, v.45, n.4, p.1026-1048. 2012.

W-5.

W-5. Correio Paulistano, p.4. 29 set. 1934.

\section{$\rightarrow \rightarrow \rightarrow<<<$}

